\title{
A Self-Assessment and Peer Feedback Tool for Leader Development
}

\author{
Erin S. Barry \\ Uniformed Services University \\ John E. McManigle \\ Duke University \\ John E. McManigle \\ Uniformed Services University
}

\begin{abstract}
Self-awareness is essential to leader development. Internal self-awareness refers to how well we see and understand ourselves and our impact on others. External self-awareness refers to the extent to which we understand how others see us. To optimize self-awareness, it is important to receive and provide frank and meaningful feedback. These skills can improve leader performance, increase self-awareness, and enhance development. Currently, there are few instruments that provide information about self-awareness. The creation of a self-assessment and peer feedback tool would help provide individuals with clear assessments of their leadership knowledge and skills as well as perspectives from peers with whom they work closely. This article describes the development of a self-assessment and peer feedback tool based on a LeaderFollower Framework. This tool can be used within leader development programs to enhance selfawareness and peer perceptions to further develop leaders.
\end{abstract}

Keywords: self-assessment, peer feedback, leader development assessment, leader development

\section{INTRODUCTION}

Two "meta-competencies" have been deemed important for leader growth: self-awareness and adaptability (Hall, 2004). Self-awareness is a fully conscious understanding of elements of one's identity that affect emotions, cognitions, behaviors as well as interactions and impact on others (Goleman, 1995, 2011). Self-awareness is essential to the leader development process because individuals must understand their own impact on others. Because self-awareness is vital to growth as a leader, leader development programs must be designed to enhances the learner's self-awareness.

Additionally, it is important for individuals to learn to receive and provide meaningful feedback. These skills can improve leader performance, increase self-awareness, and enhance development. Receiving feedback allows an individual to gain others' perspectives about self, which can encourage one to reflect upon how and why we come across as we do. Providing feedback to others, especially to peers, also allows one to increase self-awareness by assessing peer reactions and adjusting the feedback as needed to be useful and effective. 
The goal of healthcare education is to create self-directed learners who embrace a growth mindset and continually seek feedback to improve their performance (Dweck, 2006, 2016). Peer feedback is a source that learners can tap into that is relatively easy to access because learners work closely throughout their education. Peers can provide valuable perspectives that teachers or supervisors are unable to provide. Within education, feedback has mainly focused on instructors providing feedback to learners. Adding selfassessment and peer feedback can provide information that instructors may not have been able to evaluate, include additional perspectives, and supplement instructor assessment constrained by time and resources (Taylor \& Hamdy, 2013). Johnson et al (2016, p. 2) defined feedback as "a process in which learners seek to find out more about the similarities and differences between their performance and the target performance, so they can improve their work." This definition brings the focus of seeking feedback onto the learners versus waiting for the instructors to provide feedback. Arnold et al. (2005) studied medical students' views on peer assessment and found three themes that promoted or discouraged peer assessment: "personal struggles with peer assessment, characteristics of the assessment system itself, and the environment in which the system operates (p. 819)."

Leader development within medical education has gained interest and attention over the past decade (Barry, Grunberg, Kleber, McManigle, \& Schoomaker, 2018; Crites, Ebert, \& Schuster, 2008; Hartzell, Yu, Cohee, Nelson, \& Wilson, 2017; Lerman \& Jameson, 2018; Mafe, Menyah, \& Nkere, 2016; Quince et al., 2014; Sadowski, Cantrell, Barelski, O'Malley, \& Hartzell, 2018; Stringfellow et al., 2015; Till, McKimm, \& Swanwick, 2017; Varkey, Peloquin, Reed, Lindor, \& Harris, 2009; Webb et al., 2014) and is a critical component for success according to the Association of American Medical Colleges (Association of American Medical Colleges, n.d.). A Google search yields many results for the link between the importance of self-awareness and leadership, but there were no instruments found within these searches to provide individuals with a measure of their own self-awareness, especially with regard to their character, competence, context, and communication elements. Additionally, there is not a particular conceptual framework that currently guides medical education of leadership throughout the United States or globally.

The creation of a self-assessment and peer feedback tool is needed to help provide individuals with assessment of their own leadership knowledge and skills as well as perspectives from peers whom they work with closely (Ashley \& Reiter-Palmon, 2012). The purpose of this article is to focus on the development of a self-assessment and peer feedback tool based on a Leader-Follower Framework that has recently been developed to guide leadership education and development curriculum and assessment at the Uniformed Services University (Barry \& Grunberg, 2020; Barry et al., 2018; Callahan \& Grunberg, 2019; Grunberg et al., 2018). This tool can be used within leader development programs to enhance selfawareness and peer perceptions to further develop leaders.

\section{DESIGN}

This protocol (DBS.2021.205) was reviewed by USU Institutional Review Board and determined to be an exempt study.

\section{Conceptual Framework to Guide Effective Feedback}

To structure feedback effectively, tools, instruments, and assessments should be based on a conceptual framework that can be used to guide and structure feedback. The self-assessment and peer feedback tool described in this paper is based on the Leader-Follower Framework (Barry \& Grunberg, 2020) used at the USU in the leader and leadership education and development (LEAD) program (Barry et al., 2018). The framework includes four " $\mathrm{C}$ " elements - Character, Competence, Context, Communication which operate across four levels of psychosocial interaction - Personal, Interpersonal, Team, and Organizational (Grunberg et al., 2018). Character (Who the individual is) refers to physical and psychological aspects of the individual. Competence (What the individual knows and does) refers to role-specific knowledge and skills and to general leadership knowledge and skills. Context (When and Where leadership or followership occurs) includes physical, psychological, social, and cultural environments. Communication (How individuals interact with each other) includes sending and receiving information, verbally and nonverbally. 
Personal refers to psychological and biological aspects of the individual. Interpersonal refers to dyadic relationships and interactions. Team refers to a small group committed to common goals. Organizational refers to large groups, institutions, and systems. This self-assessment and peer feedback tool focuses specifically on the four " $\mathrm{C}$ " elements. Emotional intelligence falls under Competence within this framework, yet because it can be continuously developed and is an essential leader skill, it has been pulled out as a separate area for feedback.

\section{Initial Tool Development}

The initial tool development followed methods outlined in Artino et al. (2014) and those steps outlined in Finn and Garner (2011). These pre-testing methods include developing the items and conducting expert validation. Initial pre-testing took place with medical students during required education sessions on feedback (three different classes [ $\mathrm{N}>160$ learners per class] during pre-clerkship and one class repeated the input post-clerkship). Learners were told that a self-assessment and peer feedback tool was being developed and their input was being solicited to allow for the creation of a tool that they would find useful to assess themselves and their peers to assist with leader development.

Small groups of learners reviewed and rated questions initially developed for faculty to rate learner leader performance (Moosey, 2016) to determine how useful the questions would be for providing peer feedback (Arnold et al., 2005; Finn \& Garner, 2011). The 24 questions in the faculty tool fell into four categories based on the Leader-Follower Framework - Character, Competence, Context, Communication (Grunberg et al., 2018). Learners were divided into small groups (4-5 learners per group) and each group was given a selection of 12 of the 24 questions to rate the value of feedback from a peer for each question on a 5-point scale (from not at all valuable to extremely valuable). No group received the same 12 questions and all questions were rated. Additionally, learners submitted additional questions that would be valuable for peer feedback. This process was repeated four times with three separate medical school classes of learners during pre-clerkship; one class repeated the ratings a second time during post-clerkship to determine if clerkship provided any additional information to include.

All data were compiled by class (all data was anonymous and deidentified), and average ratings for each of the 24 questions was calculated. Based on this division of question, each of the 24 questions was rated by greater than $40 \%$ of the groups with all four classes. An overall average was calculated from the four sessions to determine themes that were valuable and not valuable for peer assessment (See Appendix 1 for questions learners ranked). Learners also provided additional themes or questions that should be considered for peer feedback which were reviewed. These additional themes/questions were compiled and those that were suggested multiple times were added. Additionally, many learner comments suggested rewording of the questions and to add in other elements from the Leader-Follower Framework.

\section{Self-Assessment and Peer Feedback Tool}

Based on anonymous ratings and comments from learners, all questions were reviewed (EB, JM) to determine themes that were important to retain, those that should be removed, and additional ones to be added. The co-authors used the average scores for each question to help make decisions on whether to keep questions with averages greater than three. Questions that had an average less than three were discussed to determine if they should be kept or reworded. Several questions were reworded (by EB, JM) after this step based on learner feedback. Additionally, the tool was reviewed by four experts in survey design and leader development as expert reviewers. Double barreled questions were removed and the wording was finalized.

The final version of the survey (see Table 1 and Appendix 2 for the full tool) includes 30 questions with an additional two to be asked during the peer part of the tool. A custom web interface, previously developed to administer $360^{\circ}$ evaluations (Murphy et al., 2016) was refined and deployed to administer this survey. Using industry-standard building blocks including the Apache web server (Apache Software Foundation, Wilmington, DE), MySQL database server (Oracle Corporation, Austin, TX), PHP hypertext preprocessor (The PHP Group), and jQuery UI interface library (OpenJS Foundation), the interface presented survey questions in random order. Answers were solicited via a "slider" on a visual analog scale, and recorded internally on a scale of 0-100 not visible to respondents. The visual analog scale was anchored 
with annotations of "Growth" (0-30), "Solid" (30-70), and "Excels" (70-100). Cryptographic user tokens were provided to each participant to prevent identification of survey participants and subjects. The system calculated group means for each " $\mathrm{C}$ " element and generated a custom report for each participant after the conclusion of the survey window.

TABLE 1

LIST OF QUESTIONS INCLUDED IN THE SELF-ASSESSMENT/PEER FEEDBACK TOOL

\begin{tabular}{|c|c|}
\hline \multirow{7}{*}{ Communication } & I effectively use verbal communication at the Interpersonal level \\
\hline & I effectively use verbal communication at the Team level \\
\hline & I effectively listen to others \\
\hline & I effectively communicate a common goal/vision to team members \\
\hline & I effectively demonstrate non-verbal communication \\
\hline & I receive feedback from others positively \\
\hline & I integrate feedback from team members \\
\hline \multirow{7}{*}{ Competence } & I incorporate input from team members to effectively solve problems \\
\hline & I use available information to make decisions \\
\hline & I make efficient use of the time \\
\hline & I appropriately prioritize tasks \\
\hline & I effectively demonstrate role specific skills \\
\hline & I effectively resolve conflict \\
\hline & I effectively demonstrate adaptability \\
\hline \multirow{5}{*}{ Character } & I lead by example \\
\hline & I accurately attribute accountability for team accomplishments or failures \\
\hline & I consistently demonstrate integrity \\
\hline & I remain effective in stressful situations \\
\hline & I am trustworthy \\
\hline \multirow{6}{*}{ Context } & I demonstrate situational awareness \\
\hline & I address problems creatively in response to changing conditions \\
\hline & I demonstrate cultural sensitivity \\
\hline & I am open to the perspectives of others \\
\hline & I adapt well to stressful situations \\
\hline & I adapt my role as a leader or follower based on context \\
\hline \multirow{5}{*}{$\begin{array}{l}\text { Emotional } \\
\text { Intelligence }\end{array}$} & I have a high degree of self-awareness \\
\hline & I exhibit a high degree of self-management \\
\hline & I have a well-developed sense of social-awareness \\
\hline & I demonstrate strong relationship-management skills \\
\hline & $\begin{array}{l}\text { I demonstrate that I am motivated to be the best uniformed health medical officer } \\
\text { that I can be }\end{array}$ \\
\hline \multirow{2}{*}{ Peer Questions } & If I form a team, I would choose this person as a leader \\
\hline & If I form a team, I would choose this person as a follower \\
\hline
\end{tabular}

This tool was administered to a new group of learners: two classes of medical students $(\mathrm{N}>160$ learners per class; one first year and one second year class) during the pre-clerkship period and feedback was collected. Learners had worked together in small groups (3-4 learners per group) closely for months so they had experience from which to provide meaningful ratings of each other.

Learners rated themselves and 2-3 peers with whom they had worked closely for several months. Following the administration of the tool, each learner received an individual report and a session was given 
to the learners regarding how to provide effective feedback. During the session, learners were given information about what feedback is, guidelines to provide feedback through observation, sharing details about that observation, and then allowing the person receiving feedback to understand and ask clarifying questions so that they understand and can know how to make changes (Rudolph, Simon, Rivard, Dufresne, $\&$ Raemer, 2007). Then learners worked with their small groups (those 3-4 learners to whom they provided feedback) and practiced giving and receiving peer feedback. At the end of the session, each learner was asked to identify one item that they would like to work on. This area for growth was shared with their small groups so that peers could continually provide feedback to each other for continual improvement. After the session, an anonymous follow-up survey was sent to the learners to ask their thoughts about using the tool.

\section{RESULTS}

From a first-year medical school class of 177 learners, we received 71 responses ( $40.1 \%$ response rate). Of those who answered the post-session survey, $97.2 \%$ and $97.2 \%$ considered self-assessment and peer counseling/feedback an important aspect of leader development, respectively. $97.2 \%$ of the learners thought that the tool was consistent with the Leader-Follower Conceptual Framework. 77.5\% of learners thought that the tool increased their self-awareness. $85.9 \%$ of learners were comfortable using the tool; $87.3 \%$ were comfortable providing feedback to their peers; $87.3 \%$ were comfortable receiving feedback. $87.3 \%$ thought the small group discussion with their peers was useful; $91.5 \%$ thought the feedback they received from their peers was useful.

From a second-year medical school class of 171 learners, we received 83 responses $(48.5 \%$ response rate). Of those who answered the post-session survey, $86.7 \%$ and $91.6 \%$ considered self-assessment and peer counseling/feedback an important aspect of leader development, respectively. $95.2 \%$ of the learners thought that the tool was consistent with the Leader-Follower Conceptual Framework. 80.7\% of learners thought that the tool increased their self-awareness. $89.2 \%$ of learners were comfortable using the tool; $92.8 \%$ were comfortable providing feedback to their peers; $96.4 \%$ were comfortable receiving feedback. $78.3 \%$ thought the small group discussion with their peers was useful; $88 \%$ thought the feedback they received from their peers was useful.

\section{DISCUSSION}

The purpose of this project was to develop a self-assessment and peer feedback tool to help increase learner's self-awareness and address medical students' perspectives on peer assessments (Arnold et al., 2005). Self-awareness is the accurate perceptions of one's own actions, thoughts, and emotions and the ability to understand how you may act or think in different contexts (Bradberry \& Greaves, 2009). Additionally, self-awareness can be split into internal and external self-awareness to provide additional insight. "Internal self-awareness refers to how clearly we see our own values, passions, aspirations, fit with our environment, reactions (including thoughts, feelings, behaviors, strengths, and weaknesses), and impact on others. External self-awareness refers to how other people view us, in terms of the same aspects (Eurich, 2018)." Using self-assessment and peer feedback, internal self-awareness is one's own reflection about actions and thoughts, whereas peer feedback is the external self-awareness that allows one to see other's perspectives of one's behaviors. These two aspects of self-awareness can help in leader development.

The internal self-awareness, or the learner's self-ratings, provided them with a way to assess their own abilities. One learner stated, "It helped measure something I do not measure myself." Additionally, increasing self-awareness can help learners become better team members in all capacities. Learners were able to see the importance and stated, "It makes me aware of what I can work on to be a better team member/leader," and "I am more aware of how my setbacks as an individual affect my fire team."

Most of the comments from the learners focused on external self-awareness, or ratings/comments from peers. Many of the learners said that discussing with their teammates brough awareness to action and behaviors of which they were unaware themselves. Some example statements from learners are, "My team members pointed out things that I didn't notice," "It brought to light some more areas that I did not know I 
struggled with," "My team made me aware of strengths and weaknesses I didn't know I had," and "There are aspects of your character and personality that can only be exposed by other people. My teammates provided valuable insight into who I am as a person and as a professional."

Additionally, the tool was able to bring about awareness in the ratings of self versus the ratings from peers. Learners said "[The tool] Showed discrepancy between self-critique and perception by others," "I was able to compare my evaluation to that of my peers," "It was very helpful gauging where I rated myself in comparison to those in my group who have observed me in stressful situations over a long period of time," and "We don't often give each other feedback, so often we go on thinking we are doing really well or really bad based on how we think we are doing compared to others - our perception may not be the reality. Sometimes we are harsh critics of ourselves."

Building on the awareness, the discussion with peers was valuable to determine the effects of those peer perceptions. Learners said, "I was able to understand how my actions are perceived by others better," "It made me realize how you can be perceived differently from different person," "It was helpful to get a sense of how others perceive me in comparison to how I view myself," "It helps me to see outside perspectives of my actions and words," "I got to see how others see me. Sometimes the things I thought I was weak in, others actually saw as a strong point," and "I thought that I was a good follower but found that was something I was rated lower on, my teammates explained why I might not be perceived as a good follower and how to overcome that."

Learners found the tool itself useful for multiple reasons. For example, "[The tool] Provided a framework for dialogue that leads to a greater understanding of myself," "The survey itself was a great tool to increase my own self-awareness as it asked questions that allowed me to reflect on myself and by receiving feedback from my peers, able to see what I could not see," and "This tool is helpful because it not only quantifies different traits that we possess but also provides a framework to receive constructive criticism from our peers."

It is extremely important that learners have formed trust within their group with all members. When trust is not there, learners are less likely to provide open, honest feedback with each other (Arnold et al., 2005). For example, learners said, "I think the idea behind the session is great in theory; however, it appeared that my members were unable to explain why they rated me so poorly. When I questioned my team members asking how they came to the rating, one team member stated, 'We only see each other in anatomy lab, so I do not feel comfortable giving feedback since I just know you in that limited aspect.' The issue stems from the fact that our team has experienced some conflict that we are working through; thus, it appears the reviews were essentially biased and not necessarily based on performance," "Unfortunately none of my fire team peers were motivated to provide any comments on 'opportunities' for anyone's performance. I was the only member who tried to give constructive comments to my peers rather than just compliments, which left me frustrated as it hindered the whole purpose of the exercise," "The team member at the heart of tensions refused to give feedback because, 'I don't feel y'all are ready to take and accept feedback.' It's hard to make improvements when people aren't willing to communicate during a session specifically design for us to communicate with each other."

There are a few limitations of the present study. The self-assessment and peer coaching tool is based entirely on the Leader-Follower Framework that is used at the Uniformed Services University to guide curriculum and assess learners. This tool was tested at a single institution and with a single population (medical students). The post survey received a limited response rate, but is comparable to other survey response rates within the university. Finally, the small group discussions were not facilitated by faculty to allow learners to share without the presence of faculty they may perceive as evaluating them, yet some groups asked for more structure or a facilitator to be present.

Future studies should assess healthcare providers at different points in their careers to determine if the tool is valuable at different stages of the professional life-cycle. Additionally, it would be useful to include additional populations to determine if the tool is valuable for others, not just healthcare populations. It would also be useful to link quantitative and qualitative data together to determine if there is a correlation between the two. 


\section{CONCLUSIONS}

Overall, learners enjoyed the tool and follow-on activity to receive and provide peer feedback. Many learners found value in discussing differences between their own self-perception and the perception of their peers. It has been an eye-opening experience and hopefully one that allows them to create a growth mindset. Continuing to garner student buy-in is essential to the process of open, honest feedback to each other. This self-assessment and peer feedback tool is one that can be used in any leader development setting. The tool provides a way to self-assess and also receive feedback from peers.

\section{ACKNOWLEDGEMENT}

The opinions and assertions contained herein are the sole ones of the authors and are not to be construed as reflecting the views of the Uniformed Services University or the Department of Defense. We thank the students, faculty, and staff who participated in this military medical field practicum.

\section{REFERENCES}

Arnold, L., Shue, C.K., Kritt, B., Ginsburg, S., \& Stern, D.T. (2005). Medical students' views on peer assessment of professionalism. Journal of General Internal Medicine, 20(9), 819-824.

Artino, A.R., Jr., La Rochelle, J.S., Dezee, K.J., \& Gehlbach, H. (2014). Developing questionnaires for educational research: AMEE Guide No. 87. Medical Teacher, 36(6), 463-474.

Ashley, G.C., \& Reiter-Palmon, R. (2012). Self-awareness and the evolution of leaders: The need for a better measure of self-awareness. Journal of Behavioral and Applied Management, 14(1), 2.

Association of American Medical Colleges. (n.d.). About leadership development. Retrieved from https://www.aamc.org/members/leadership/about/

Barry, E.S., \& Grunberg, N.E. (2020). A conceptual framework to guide leader and follower education, development, and assessment. Journal of Leadership, Accountability, and Ethics, 17(1), 127-134. doi:https://doi.org/10.33423/jlae.v17i1.2795

Barry, E.S., Grunberg, N.E., Kleber, H.G., McManigle, J.E., \& Schoomaker, E.B. (2018). A four-year medical school leader and leadership education and development program. International Journal of Medical Education, 9, 99. Retrieved from https://www.ncbi.nlm.nih.gov/pmc/articles/PMC5951783/pdf/ijme-9-99.pdf

Bradberry, T., \& Greaves, J. (2009). Emotional Intelligence 2.0. San Diego, CA: TalentSmart.

Callahan, C.W., \& Grunberg, N.E. (2019). Military Medical Leadership. In F.G. O'Connor, E.B. Schoomaker, \& D.C. Smith (Eds.), Fundamentals of Military Medicine (pp. 51-66). San Antonio, TX: Borden Institute.

Crites, G.E., Ebert, J.R., \& Schuster, R.J. (2008). Beyond the dual degree: Development of a five-year program in leadership for medical undergraduates. Academic Medicine, 83(1), 52-58.

Dweck, C.S. (2006). Mindset: The new psychology of success. New York, NY: Penguin Random House LLC.

Dweck, C.S. (2016). What having a "growth mindset" actually means. Harvard Business Review. Retrieved from https://hbr.org/2016/01/what-having-a-growth-mindset-actually-means

Eurich, T. (2018). What self-awareness really is (and how to cultivate it). Retrieved from https://hbr.org/2018/01/what-self-awareness-really-is-and-how-to-cultivate-it

Finn, G.M., \& Garner, J. (2011). Twelve tips for implementing a successful peer assessment. Medical Teacher, 33(6), 443-446.

Goleman, D. (1995). Emotional intelligence: Why it can matter more that IQ. New York, NY: Bantam Dell.

Goleman, D. (2011). Leadership: The power of emotional intelligence. Northampton, MA: More than Sound. 
Grunberg, N.E., Barry, E.S., Callahan, C., Kleber, H.G., McManigle, J.E., \& Schoomaker, E.B. (2018). A conceptual framework for leader and leadership education and development. International Journal of Leadership in Education, pp. 1-7. doi:https://doi.org/10.1080/13603124.2018.1492026

Hall, D.T. (2004). Self-awareness, identity, and leader development. In Leader development for transforming organizations (pp. 173-196). Psychology Press.

Hartzell, J.D., Yu, C.E., Cohee, B.M., Nelson, M.R., \& Wilson, R.L. (2017). Moving beyond accidental leadership: A graduate medical education leadership curriculum needs assessment. Military Medicine, 182(7), e1815-e1822. Retrieved from https://academic.oup.com/milmed/articleabstract/182/7/e1815/4158583?redirectedFrom=fulltext

Johnson, C.E., Keating, J.L., Boud, D.J., Dalton, M., Kiegaldie, D., Hay, M., . . Nestel, D. (2016). Identifying educator behaviours for high quality verbal feedback in health professions education: Literature review and expert refinement. BMC Medical Education, 16(1), 96.

Lerman, C., \& Jameson, J.L. (2018). Leadership Development in Medicine. N Engl J Med, 378(20), 1862-1863. doi:10.1056/NEJMp1801610

Mafe, C., Menyah, E., \& Nkere, M. (2016). A proposal for health care management and leadership education within the UK undergraduate medical curriculum. Advances in Medical Education and Practice, 7, 87.

Moosey, M.J. (2016). Military medical leadership in uniformed medical students: Creating a new assessment instrument using the Delphi method. Uniformed Services University of the Health Sciences, Bethesda, MD.

Murphy, K.R., McManigle, J.E., Wildman-Tobriner, B.M., Jones, A.L., Dekker, T.J., Little, B.A., . . . Taylor, D.C. (2016). Design, implementation, and demographic differences of HEAL: A selfreport health care leadership instrument. Journal of Healthcare Leadership, 8, 51.

Quince, T., Abbas, M., Murugesu, S., Crawley, F., Hyde, S., Wood, D., \& Benson, J. (2014). Leadership and management in the undergraduate medical curriculum: A qualitative study of students' attitudes and opinions at one UK medical school. BMJ Open, 4(6), e005353.

Rudolph, J.W., Simon, R., Rivard, P., Dufresne, R.L., \& Raemer, D.B. (2007). Debriefing with good judgment: Combining rigorous feedback with genuine inquiry. Anesthesiology Clinics, 25(2), 361-376.

Sadowski, B., Cantrell, S., Barelski, A., O’Malley, P.G., \& Hartzell, J.D. (2018). Leadership Training in Graduate Medical Education: A Systematic Review. Journal of Graduate Medical Education, 10(2), 134-148.

Stringfellow, T.D., Rohrer, R.M., Loewenthal, L., Gorrard-Smith, C., Sheriff, I. H., Armit, K., . . . Spurgeon, P.C. (2015). Defining the structure of undergraduate medical leadership and management teaching and assessment in the UK. Medical Teacher, 37(8), 747-754.

Taylor, D.C., \& Hamdy, H. (2013). Adult learning theories: Implications for learning and teaching in medical education: AMEE Guide No. 83. Medical Teacher, 35(11), e1561-e1572.

Till, A., McKimm, J., \& Swanwick, T. (2017). Twelve tips for integrating leadership development into undergraduate medical education. Medical Teacher, pp. 1-7.

Varkey, P., Peloquin, J., Reed, D., Lindor, K., \& Harris, I. (2009). Leadership curriculum in undergraduate medical education: A study of student and faculty perspectives. Medical Teacher, $31(3), 244-250$.

Webb, A.M., Tsipis, N.E., McClellan, T.R., McNeil, M.J., Xu, M., Doty, J.P., \& Taylor, D.C. (2014). A first step toward understanding best practices in leadership training in undergraduate medical education: a systematic review. Academic Medicine, 89(11), 1563-1570. 


\section{APPENDIX 1}

As a team, please rate the value of feedback from a peer in response to each question, $1=$ not al all valuable; $2=$ slightly valuable; $3=$ somewhat valuable; $4=$ valuable; $5=$ extremely valuable

\begin{tabular}{|c|c|c|c|c|c|c|}
\hline & & 1 & 2 & 3 & 4 & 5 \\
\hline 1 & $\begin{array}{l}\text { Oral communication includes skills, and behaviors to express } \\
\text { information by speaking and have that information understood } \\
\text { by the intended recipient(s). } \\
\text { How often does your peer demonstrate effective oral } \\
\text { communication? }\end{array}$ & & & & & \\
\hline 2 & $\begin{array}{l}\text { Non-verbal communication includes behaviors to complement } \\
\text { verbal communication so the information conveyed is better } \\
\text { understood by the intended recipient(s) (e.g., hand gesture, eye } \\
\text { contact, body posture). } \\
\text { How often does your peer demonstrate effective non-verbal } \\
\text { communication? }\end{array}$ & & & & & \\
\hline 3 & $\begin{array}{l}\text { Written communication includes skills and competencies to } \\
\text { effectively convey information through written words or } \\
\text { symbols and that the information is understood by the intended } \\
\text { recipient(s). } \\
\text { How often does your peer demonstrate effective written } \\
\text { communication? }\end{array}$ & & & & & \\
\hline 4 & $\begin{array}{l}\text { Listening effectively includes attention, information processing, } \\
\text { and behaviors to understand audible communication. } \\
\text { How often does your peer demonstrate effective listening? }\end{array}$ & & & & & \\
\hline 5 & $\begin{array}{l}\text { Collaborating includes attitudes and behaviors to effectively } \\
\text { work with other. } \\
\text { How often does your peer demonstrate collaboration? }\end{array}$ & & & & & \\
\hline 6 & $\begin{array}{l}\text { Motivating others involves influencing others to care about and } \\
\text { work to achieve individual and group goals? } \\
\text { How often does your peer demonstrate motivation of others? }\end{array}$ & & & & & \\
\hline 7 & $\begin{array}{l}\text { Mentoring includes guiding and advising others. } \\
\text { How often does your peer demonstrate mentoring of others? }\end{array}$ & & & & & \\
\hline 8 & $\begin{array}{l}\text { Problem solving includes skills to effectively identify a problem } \\
\text { (clinical, academic, or military), integrate background } \\
\text { knowledge of the problem, brainstorm possible solutions and } \\
\text { hypotheses, and determine what additional information is } \\
\text { needed to solve the problem. } \\
\text { How often does your peer demonstrate effective problem } \\
\text { solving? }\end{array}$ & & & & & \\
\hline 9 & $\begin{array}{l}\text { Decision making includes thought processes identifying and } \\
\text { selecting the best course of action among more than one } \\
\text { alternative. } \\
\text { How often does your peer demonstrate effective decision } \\
\text { making? }\end{array}$ & & & & & \\
\hline 10 & $\begin{array}{l}\text { Time management involves effectively allocating time to } \\
\text { successfully execute a task or mission. } \\
\text { How often does your peer demonstrate effective time } \\
\text { management? }\end{array}$ & & & & & \\
\hline 11 & $\begin{array}{l}\text { Learning effectively involves attitudes and behaviors to gain } \\
\text { new knowledge and skills or to build upon past knowledge and } \\
\text { skills? } \\
\text { How often does your peer demonstrate learning? }\end{array}$ & & & & & \\
\hline
\end{tabular}




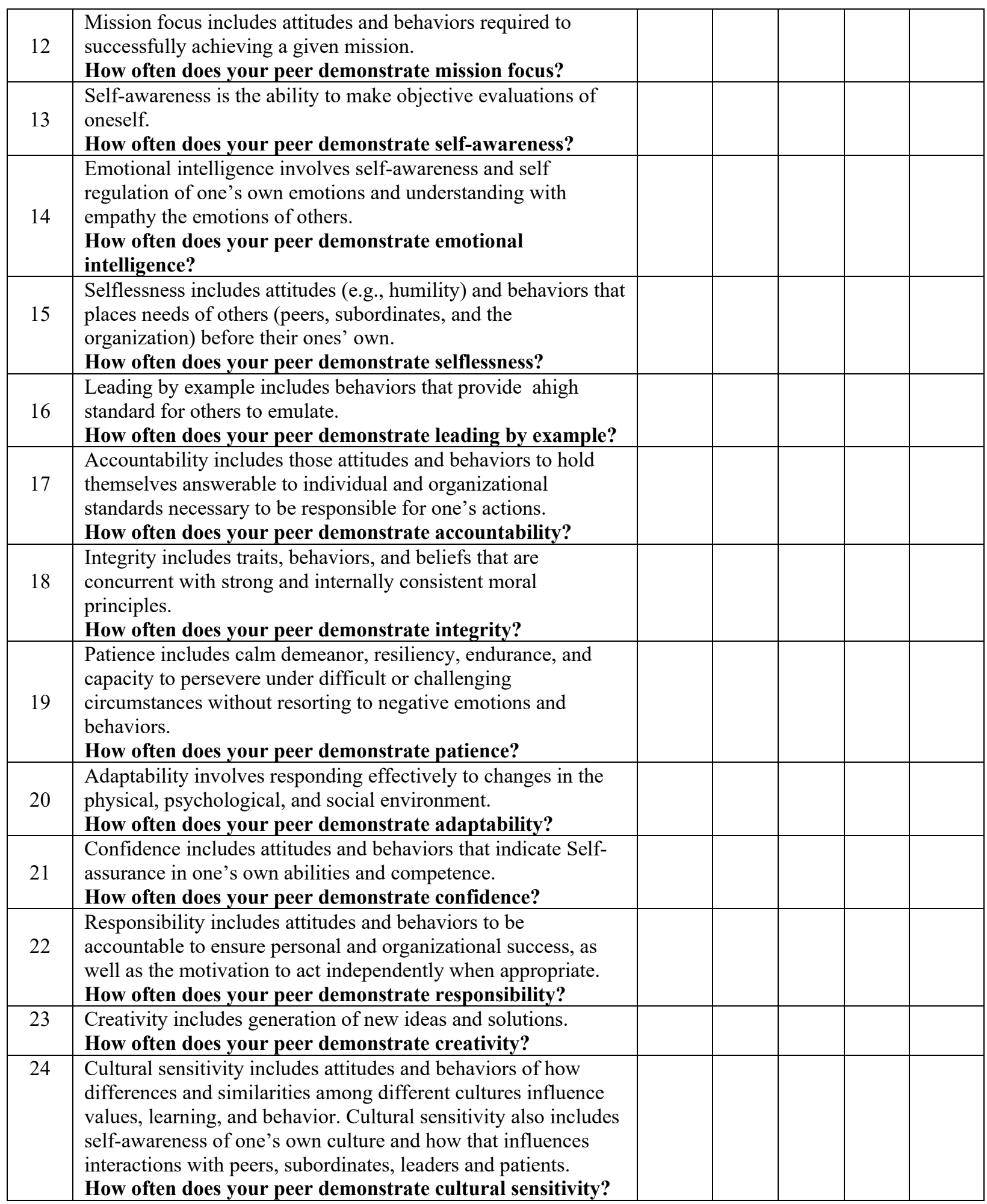

Questions $(\mathrm{N}=24)$ ranked by learners to determine themes that were valuable and not valuable for peer assessment. 


\section{APPENDIX 2}

\section{Self-Assessment / Peer Feedback Tool}

Leadership refers to influence on individuals, teams, and groups by enhancing behaviors (actions), cognitions (thoughts and beliefs), and motivations (reasons for actions and thoughts) to achieve common goals. For effective team performance, leaders must be adaptive and able to serve as effective followers and followers must be able to assume leadership roles when appropriate.

The Leader-Follower Framework identifies four major elements of leadership across four levels of interaction. The four ' $\mathrm{C}$ ' elements address who (Character), what (Competence), where \& when (Context), and how (Communication) of leadership and followership at the Personal, Interpersonal, Team, and Organizational psychosocial levels.

The Self-Assessment / Peer Feedback Survey Tool, and associated activities, are designed to promote the following educational objectives:

1. The Leader-Follower Framework is intended to be a tool-kit containing essential 'tools' for effective leadership and followership. Applying the 'tools' contained within Character, Competence, Context, and Communication across the psychosocial levels will enhance team function.

2. To develop as a leader and follower, it is important to be self-aware and honest with ourselves. In addition, it is critical to be aware of how others perceive us. This survey tool affords the opportunity for self-reflection and to share perceptions with team members.

3. The ability to provide feedback and support to peers (aka leading horizontally) is a vital competency for leaders and followers to master. The Self-Assessment / Peer Feedback activities introduce the concept of 'Peer Feedback'; and afford an opportunity to both provide and receive peer feedback.

4. The ultimate goal is to enhance the development of uniformed health officers, comfortable and competent to function as health care leaders and followers in both peace-time and operational environments. Understanding and implementing the Leader-Follower Framework tools, becoming more self-aware and able to provide and receive peer feedback are essential steps on this journey.

Please rate yourself (or your team member) on each of the following questions on a sliding scale ranging from "Growth" to "Excels." The Survey uses a 'Visual Analog Scale' that allows you to rate yourself and team members along a continuum. There is no 'pass' and no 'fail'. This activity has nothing to do with academic grading and is not designed to be a 'rack and stack' exercise. The purpose, as outlined above, is to enhance self-awareness and provide a platform for self and peer development. If you believe you (or your team member) could significantly improve in a specific area, then your rating should go in the "Growth" range; if you believe you (or your team member) are remarkably strong in an area, then your rating should go in the "Excels" range. Many of the self and peer ratings may be in the "Solid" range. With the sliding scale, the relative strength of "Solid" ratings can be reflected as stronger (towards "Excel" range) or weaker (towards "Growth" range). None of the points on the rating points are equal to a failure; we all have the ability to grow. 


\section{Communication}

In the Leader-Follower Framework, Communication includes verbal and non-verbal, sending and receiving. As military and public health medical officers, effective Communication is critical at the Interpersonal level as well as the Team and Organizational levels.

- $\quad$ I effectively use verbal communication at the Interpersonal level.

o Communication at the Interpersonal level - one-on-one with patient, colleague, peer, senior leader, staff, others - is a core leadership competency for leaders and followers, officers and healthcare providers.

\begin{tabular}{cc|c} 
Growth & Solid & Excels
\end{tabular}

- $\quad$ I effectively use verbal communication at the Team level.

o The majority of a healthcare or military career is spent as a team member. Effective communication with all members of team is essential for success.

\begin{tabular}{l|l|l} 
Growth & Solid
\end{tabular}

- $\quad$ I effectively listen to others.

- Communication is sending and receiving, verbal and non-verbal. Receiving and considering input from others is an important part of communication.

\begin{tabular}{l|l|l} 
Growth & Solid & Excels
\end{tabular}

- I effectively communicate a common goal/vision to team members.

o The ability to communicate a vision or goal in a manner that motivates teams and organizations to work cooperatively toward a common goal is essential for effective leadership. The leader is in a unique position to effectively craft and communicate the team vision or goal. Followers must also be able to effectively communicate team goals.

\begin{tabular}{l|l|l} 
Growth & Solid & Excels
\end{tabular}

- I effectively demonstrate non-verbal communication.

- Information "sent" and "received" through body language, facial expression, eye contact and other nonverbal mannerisms is often more powerful than the spoken message. Non-verbal communication should be consistent with verbal message. Leaders and followers must be aware of the non-verbal messages they send and sensitive to how they are received.

Growth Solid Excels

- $\quad$ I receive feedback from others positively.

o Being open to receive feedback - both positive and negative - positively from others is important for continued self-development and team success.

Growth Solid Excels

- $\quad$ I integrate feedback from team members.

o Being able to receive feedback from team members and integrate that feedback is important for effective team function. Strong leaders and followers must "hear" what others are communicating - both verbally and non-verbally. The inability to solicit and process feedback can be a fatal flaw.

\begin{tabular}{|c|c|c|}
\hline Growth & Solid & Excels \\
\hline
\end{tabular}

Estimated Average for Communication

\begin{tabular}{ll|l} 
Growth & Solid & Excels
\end{tabular}

12 Journal of Leadership Accountability and Ethics Vol. 18(4) 2021 


\section{Competence}

In the Leader-Follower Framework, Competence is characterized as role-specific knowledge and skills (e.g. related to being a healthcare provider or uniformed medical officer) and transcendent knowledge and skills (e.g., critical thinking, decision making, problem solving, motivating others, emotional intelligence). Role-specific and transcendent knowledge and skills can be learned, refined, and honed with experience and effort.

- $\quad$ I incorporate input from team members to effectively solve problems.

- Effective problem solving includes skills to identify a problem (clinical, academic, or military), integrate background knowledge of the problem, brainstorm possible solutions and hypotheses, and determine and incorporate additional information is needed to solve the problem. It is important for leaders and followers to be able to collaborate in problem solving.

\begin{tabular}{l|l|l} 
Growth & Solid & Excels
\end{tabular}

- $\quad$ I use available information to make decisions.

- Decision-making includes thought processes identifying and selecting the best course of action among more than one alternative. Often decisions must be made with available information, weighing benefits and risks.

\begin{tabular}{ll|l} 
Growth & Solid & Excels
\end{tabular}

- I make efficient use of the time.

o Team members use their time wisely and do not waste others' time.

\begin{tabular}{ll|l} 
Growth & Solid & Excels
\end{tabular}

- I appropriately prioritize tasks.

o Effective leaders and followers identify what tasks are important and complete these tasks in order of importance.

- I effectively demonstrate role specific skills.

- It is important to possess and utilize the skills necessary to competently complete function as a team member. Whether as a student, a healthcare provider, or a uniformed officer.

Growth Solid Excels

- $\quad$ I effectively resolve conflict.

o Conflict occurs in many forms: personal, interpersonal, value driven, cultural, commitment to goal, team, and many others. To optimize team performance, leaders and followers must be able to identify and effectively resolve team conflict. Failure to effectively address conflict commonly leads to failure to achieve goals.

Growth Solid Excels

- I effectively demonstrate adaptability.

- Plans often do not go as one originally thinks they will, either in personal, professional, or even academic life. Individuals should adjust to contextual changes and not become overly stressed when changes occur. Team members must adapt to changes and challenges.

\begin{tabular}{|c|c|c|}
\hline Growth & Solid & Excels \\
\hline \multicolumn{3}{|c|}{ Estimated Average for Competence } \\
\hline Growth & Solid & Excels \\
\hline
\end{tabular}




\section{Character}

In the Leader-Follower Framework, Character refers to all aspects of one's character including but not limited to demographics, attributes, personality, attitudes, values, integrity and physical characteristics. Self-awareness of ones' character is critical to be successful.

- I lead by example.

o An essential quality of leadership and followership is demonstrating leading by example, in words and in actions. Team members must consistently and effectively lead through their everyday actions.
Growth
Solid
Excels

- I accurately attribute accountability for team accomplishments or failures.

- Great team members take responsibility for actions and plans that may not end up as desired. When an individual takes responsibility, they are accountable and do not place blame on others for failures. They give or share credit where deserved for team accomplishments. This responsibility is shown in both words and actions.

\begin{tabular}{l|l|l} 
Growth & Solid & Excels
\end{tabular}

- I consistently demonstrate integrity.

- Individuals with integrity are truthful and do what is right, even when this might be difficult. Leaders and followers with integrity demonstrate through words and actions and that they can be relied on to be consistent.
Growth
Solid
Excels

- I remain effective in stressful situations.

- It is essential that team members remain calm and effective in stressful situations. This is essential so that the team members can rely on each other in difficult situations.

\begin{tabular}{ll|l} 
Growth & Solid & Excels
\end{tabular}

- I am trustworthy.

o A trustworthy person is one who I would trust the health and well-being of my family as their caregiver. A trustworthy person is one who I would believe in to lead a team or be valuable team member.

\begin{tabular}{ll|l} 
Growth & Solid & Excels
\end{tabular}

Estimated Average for Character

Growth Solid Excels

14 Journal of Leadership Accountability and Ethics Vol. 18(4) 2021 


\section{Context}

In the Leader-Follower Framework, Context includes physical, psychological, social, cultural, and economic environment; changing situations; and stress that a leader may face.

- I demonstrate situational awareness.

- Situational awareness is being aware of what is going on around you. This includes environmental, human, and other factors influencing team performance.

\begin{tabular}{ll|l} 
Growth & Solid & Excels
\end{tabular}

- I address problems creatively in response to changing conditions.

- It is not only an artist who must demonstrate creativity, great leaders adapt when changes to schedule or plans arise. Effective team members must have the ability to think adaptively and not get tunnel vision when faced with unexpected problems.

Growth Solid Excels

- I demonstrate cultural sensitivity.

- We are constantly adjusting to changes in culture. We interact with people from different countries, ethnicities, races, military branches, and many other factors that contribute to cultural friction and misunderstanding.

\begin{tabular}{l|l|l} 
Growth & Solid & Excels
\end{tabular}

- I am open to the perspectives of others.

- It cannot always be "my way or the highway" instead, it is important that team members accept new ideas and give thoughtful consideration to changes and ideas as they arise.

\begin{tabular}{ll|l} 
Growth & Solid & Excels
\end{tabular}

- I adapt well to stressful situations.

- Everyone faces stress. It can be positive or negative stress. It is critical that an individual be able to function and be resilient even when faced with extreme positive or negative stressors.
Growth
Solid
Excels

- I adapt my role as a leader or follower based on context.

- Contextual and other changes may call for team member roles to change. As an impactful leader or follower, it is important to know when to step aside, or step up in order to maximize team performance. 


\section{Emotional Intelligence (EI)}

In the Leader-Follower Framework, emotional intelligence (EI) is considered a Transcendent Competency. Due to the critical importance of EI - Goleman and others state that EI is the sine qua non (a skill that is absolutely necessary) of leadership. Five specific EI focused items will be surveyed.

- I have a high degree of self-awareness.

- Self-aware individuals possess a deep and realistic understanding of their emotions, strengths, weaknesses, values and goals. They typically welcome constructive criticism and demonstrate self-confidence.

\begin{tabular}{ll|l} 
Growth & Solid & Excels
\end{tabular}

- I exhibit a high degree of self-management.

- Everyone has feelings and impulses - positive and negative. People with strong self-management recognize these feelings, control the negative, and build on the positive. Strong self-managers tend to be transparent, adaptable, optimistic, and conscientious. They also incorporate constructive criticism and adapt to new interactions and scenarios based on feedback.

\begin{tabular}{ll|l} 
Growth & Solid & Excels
\end{tabular}

- I have a well-developed sense of social-awareness.

- Social awareness is recognized at the Interpersonal level as well as Team and Organization levels. At the Interpersonal level, social awareness consists of awareness of others' feelings and emotions. At the Team and Organizational level, it requires understanding of group emotions, relationships, values, and goals. Empathy is used at this emotional intelligence level.

\begin{tabular}{ll|l} 
Growth Solid & Excels
\end{tabular}

- I demonstrate strong relationship-management skills.

- Accurately assessing and managing relationships with individuals and groups is a key component of emotional intelligence. People strong in relationship-management are often viewed as inspirational, influential, change agents, and valued collaborators.

\begin{tabular}{l|l|l} 
Growth Solid & Excels
\end{tabular}

- I demonstrate that I am motivated to be the best uniformed health medical officer that I can be.

- Motivation was originally included by Goleman as an emotional intelligence competency. It is meant to be a measure of our desire to improve and the ability to overcome challenges and obstacles to reach desired goals and outcomes. Even when difficulties arise in achieving a goal, motivation remains high.
Growth
Solid
Excels

Estimated Average for Emotional Intelligence

\begin{tabular}{ll|l} 
Growth & Solid & Excels
\end{tabular}

16 Journal of Leadership Accountability and Ethics Vol. 18(4) 2021 


\section{Only answer when rating peers}

- $\quad$ If I form a team, I would choose this person as a leader.

- We may not always get to choose our leaders, but do you feel that your peer would demonstrate (through communication and character) the type of leader that you would want to follow?

Growth Solid Excels

- If I form a team, I would choose this person as a follower.

- It is essential that teams have leaders and followers. An effective team requires team members work toward common goal. Would your peer have a positive effect on your team and be a good team member? 